DIW BERLIN

Discussion

Papers
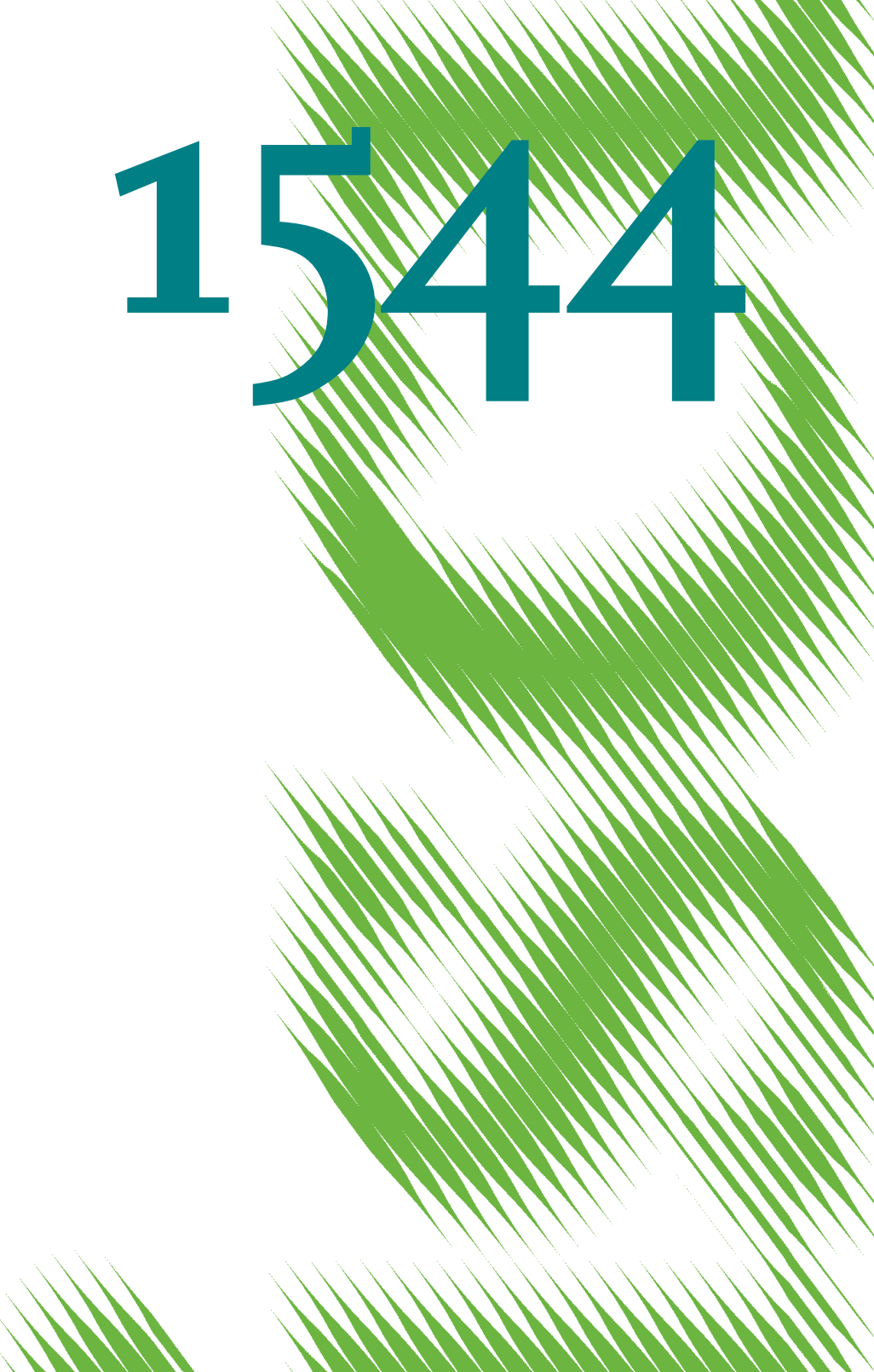

Intraday Markets for Power:

Discretizing the Continuous Trading? 
Opinions expressed in this paper are those of the author(s) and do not necessarily reflect views of the institute.

IMPRESSUM

(C) DIW Berlin, 2016

DIW Berlin

German Institute for Economic Research

Mohrenstr. 58

10117 Berlin

Tel. +49 (30) $89789-0$

Fax +49 (30) $89789-200$

http://www.diw.de

ISSN electronic edition 1619-4535

Papers can be downloaded free of charge from the DIW Berlin website:

http://www.diw.de/discussionpapers

Discussion Papers of DIW Berlin are indexed in RePEc and SSRN:

http://ideas.repec.org/s/diw/diwwpp.html

http://www.ssrn.com/link/DIW-Berlin-German-Inst-Econ-Res.html 


\title{
Intraday Markets for Power: Discretizing the Continuous Trading?
}

\author{
Karsten Neuhoff ${ }^{1}$, Nolan Ritter ${ }^{2}$, Aymen Salah-Abou-El-Enien ${ }^{3}$ \\ and Philippe Vassilopoulos ${ }^{4}$
}

\begin{abstract}
A fundamental question regarding the design of electricity markets is whether adding auctions to the continuous intraday trading is improving the performance of the market. To approach this question, we assess the experience with the implementation of the $3 \mathrm{pm}$ local auction for quarters in Germany at the European Power Exchange (EPEX SPOT) in December 2014 to assess the impact on trading volumes/liquidity, prices, as well as market depth. We discuss further opportunities and challenges that are linked with a potential implementation of an intraday auction.
\end{abstract}

Keywords: auctions, electricity, empirical analysis, market design

JEL Classification: C5, C57, C93, D44, D47, L50

\footnotetext{
${ }^{1}$ German Institute for Economic Research (DIW Berlin), Department of Climate Policy, Mohrenstrasse 58, 10117 Berlin, kneuhoff@diw.de.

${ }^{2}$ German Institute for Economic Research (DIW Berlin), Department of Climate Policy, Mohrenstrasse 58, 10117 Berlin, nritter@diw.de.

${ }^{3}$ EPEX Spot SE, Product Design, 5 Boulevard Montmartre, 75002 Paris, a.salah@epexspot.com

${ }^{4}$ EPEX Spot SE, Product Design, 5 Boulevard Montmartre, 75002 Paris, p.vassilopoulos@epexspot.com

The authors would like to thank David Newbery and Sebastian Schwenen as well as various industry experts for review comments and the German Federal Ministry for Economy Affairs and Energy for funding as part of the Project EUREEM.
} 


\section{Introduction}

Increasing shares of wind and solar generation result in increasing volumes of intraday trading pursued by market participants to adjust production schedules to updates to wind- and solar forecasts. Responding to this increasing trading volume, EPEX has implemented a first set of intraday auctions in Germany for 15 minute long products to complement the existing continuous intraday trading. This provides an opportunity to evaluate the market performance outcomes if auctions are added to continuous trading. We find that liquidity and market depth increase while price volatility declines.

These results confirm previous observations that liquidity in Central Western European power markets based on continuous intraday trading is lower than in Italy and Spain with auction based intraday trading (Hagemann and Weber, 2015). While it was previously questioned whether this increased liquidity is linked to peculiarities of these markets, our study shows that this is not the case while pointing to the importance of auctions.

Our findings are of interest for the European discussion regarding which approach to choose towards integration of intraday markets. The Capacity Allocation and Congestion Management (CACM) formulated by the European Commission allow for both, the use of continuous and auction based intraday trading. However, in recent years the Cross-Border Intraday project (XBID) only aims to link continuous trading systems, not auction based trading. Orders entered by market participants in one country are matched by orders submitted by market participants in any other country, provided there is cross-border capacity available. However, the implementation has been delayed because of complexities of the legal and technical challenges of continuous matching.

Altogether, the existing evidence may suggest that it should be re-considered whether to focus the integration of intraday markets on auction based approaches. Intraday auctions or platforms that implement auction type market clearing are already implemented for market coupling at the day ahead stage and for intraday market clearing in Spain, Italy, Ireland, Poland, and Germany with the introduction of a local auction for 15 minute $(\mathrm{mn})$ contracts. The use of intraday auctions for market coupling could also facilitate more efficient allocation of transmission capacities and could also capture scarcity values to reduce cost for consumers.

Reconsideration might also offer opportunities to harmonize bid formats. The Multi-part bidding format could allow different generation and demand offers to provide their full flexibility to the market, while limiting combinatorial complexity, and, thus, facilitating rapid market clearing. The frequency of executing intraday auctions remains to be explored.

\section{Short-term electricity trading in Central Western Europe}

Electricity is traded in Europe usually up to four years ahead of time - either bilaterally or exchange based (Chaves Avila, 2014 and Neuhoff et al., 2015a). Most short-term transactions are hosted at a day-ahead auction. In Central Western Europe (CWE), subsequently continuous bilateral and exchange based trading is pursued until gate closure, typically 30 minutes before real time. Recently an intraday auction has been added to intraday trading in Germany. Figure 1 describes the trading time-line. 


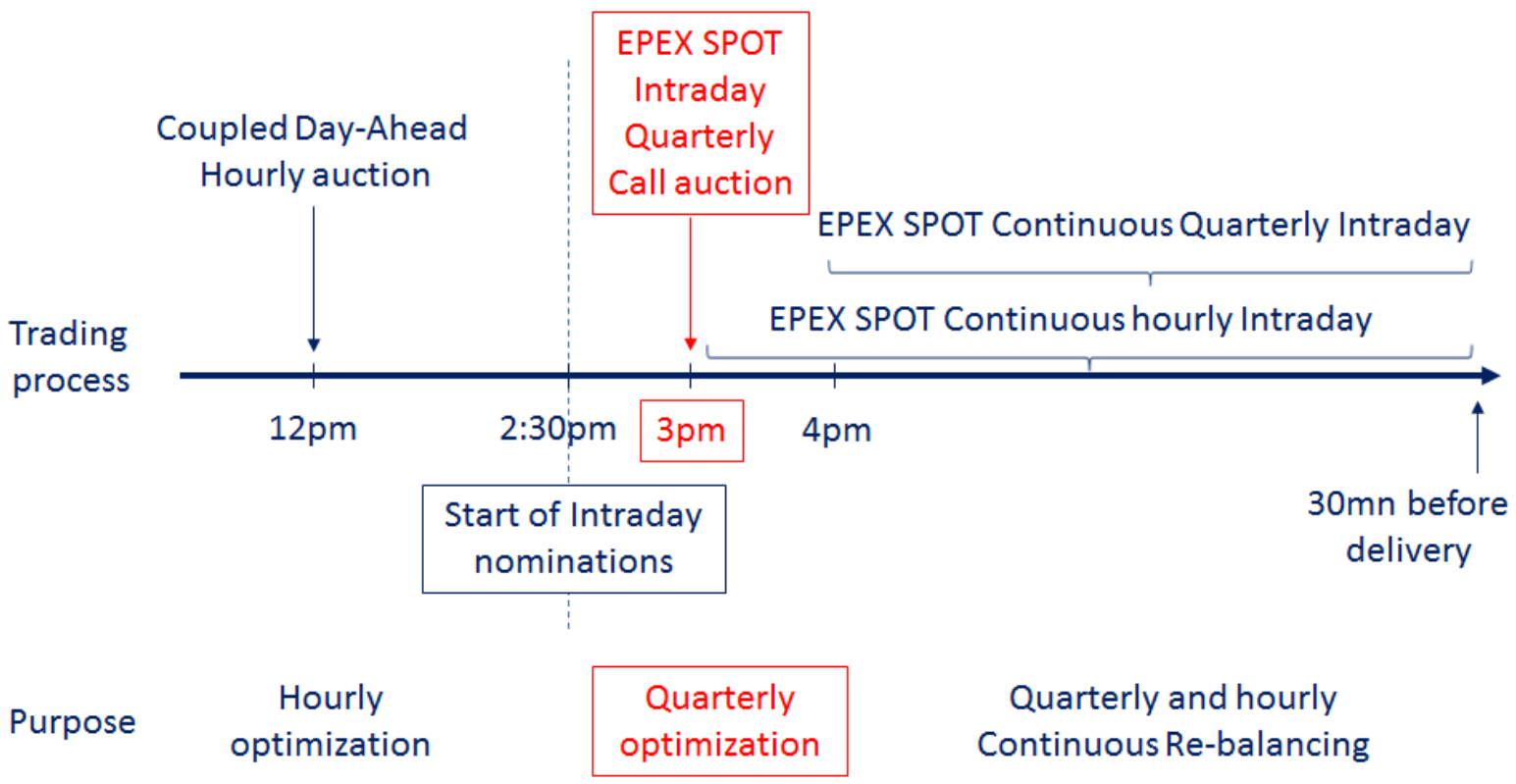

\section{Day-ahead auction}

The European Power Exchange (EPEX SPOT) organizes the short-run electricity trading starting with an auction at $12 \mathrm{pm}$ the day before delivery in one hour long slots for the 24 hours of the delivery day. For example, market participants can bid for the zone (usually country) where they are located to buy or sell a defined amount of energy for the time between $8 \mathrm{pm}$ and $9 \mathrm{pm}$ the following day. For each hour, the equilibrium price at which supply meets demand is determined and all transactions are priced accordingly (uniform pricing).

Market coupling links the results of the auctions for different zones (usually countries). If sufficient transmission capacity is available, then a common market clearing price is determined. If however such a common market clearing price would result in transmission flows exceeding the capacity between countries, then separate clearing prices are determined that ensure the flow pattern leads to the highest social welfare among participating countries.

\section{Continuous intraday trading}

In Central Western Europe, continuous trading has historically been the mechanism for exchanging power intraday. For example, in Germany continuous trading starts at $3 \mathrm{pm}$ for hourly products delivered on the following day. In addition, at $4 \mathrm{pm}$ continuous trading starts for $15 \mathrm{mn}$ products. These products allow market participants to match generation and demand for each 15 minute period so as to satisfy their balancing requirement ${ }^{4}$.

Continuous trading is shared between exchange based and bilateral trading (to our knowledge there are no active brokers in the German Intraday market yet). The volume of bilateral transactions is reported only by the national regulatory authority BNetzA with a considerable time lag (the latest report published in November 2014 shows 2013 data). In 2013, 20 Terawatt hours (TWh) were

\footnotetext{
${ }^{4}$ Vassilopoulos, P., Salah, A. (2013) describe the continuous intraday market and highlight its agility in rebalancing positions close to real-time and its ability to remunerate flexible resources.
} 
traded on the Intraday at the exchange and 15 TWh on bilateral contracts ${ }^{5}$. Although the figures are not yet available for the bilateral deals, in 201426 TWh were traded on the exchange's intraday platform.

In exchange based continuous trading, market participants can submit limit orders at any time during the trading session. They may also withdraw at any time the orders that have not been accepted. Limit orders to buy are called bids and orders to sell are called asks. A limit order specifies a price/quantity pair. An order to sell is accepted at or above the specified price. An order to buy is accepted at or below the specified price. The difference between the highest unmatched bid and lowest unmatched ask is known as the bid-ask spread.

There exist a number of other forms of orders in addition to the limit order, such as market orders, iceberg orders, or all-or-nothing orders. Market orders are used to buy or sell immediately at the best available current price, while iceberg orders consist of large orders divided into smaller order slices to conceal the total volume. All-or-nothing orders are either filled completely or not at all.

The total set of orders at a given point in time defines the order book. All market participants have access to the order book, and, therefore, know all offers that exist at the time of inquiry and that have not been executed. The order book holds the offers for the 15 minute slots, the hourly slots, and the block bids spanning several consecutive hours. Market participants can either post new orders (initiator/originator) or accept existing ones at the price specified with the order (aggressor). If a market participant initiates a new order which can be matched by the trading platform, the order is executed anonymously through the exchange and removed from the order book.

Order submissions and order withdrawals are processed one-at-a-time in order of their receipt by the exchange (serial processing), usually within milliseconds. Trade occurs whenever a new limit order is submitted that is either a buy order with a price greater than the current best ask or a sell order with a price smaller than the current best bid. In this case, the new limit order is interpreted as either fully or partially accepting one or more outstanding asks, and the execution price is the one of the initiator limit orders (pay-as-bid principle). Orders are also accepted in order of the attractiveness of their price. For identical prices, the order matched first is the one that has been sitting in the book the longest.

The continuous trading therefore implements a pay-as-bid matching algorithm in contrast to the dayahead auctions that operate under a uniform pricing rule. In uniform pricing, auction participants receive the market clearing price so that the optimal strategy in competitive environments is to bid at marginal cost. In comparison, the pay-as-bid scheme used for continuous trading implies that market participants have to anticipate the clearing price and accordingly mark up their bids.

\section{The additional intraday auction}

In December 2014, EPEX introduced an additional auction for 15 minute time slots at the beginning of the intraday trading session at $3 \mathrm{pm}$. Just as in case of the auction at $12 \mathrm{pm}$, the $3 \mathrm{pm}$ auction is a uniform price auction for the 96 quarters for following day. So far, no block-bids have been implemented in this auction.

\footnotetext{
${ }^{5}$ The BNETZA 2014 Monitoring report shows that in 2013 non-exchange electricity trading volumes amounted to 29TWh on the purchase side and 23TWh on the sale side. Of which respectively 4 and 9 TWh were intragroup trades that should be deducted.
} 
Since the introduction of the auction volumes have significantly increased, reaching more than half of total trading of 15 min products by October 2015. In the same time, the share of $15 \mathrm{mn}$ products (continuous + auction) has increased faster compared to total trading volumes (hours $+15 \mathrm{~min}$ products).

Figure 2: Volumes on the $15 \mathrm{mn}$ intraday market and the share of quarters in total trading volumes (quartersthours)

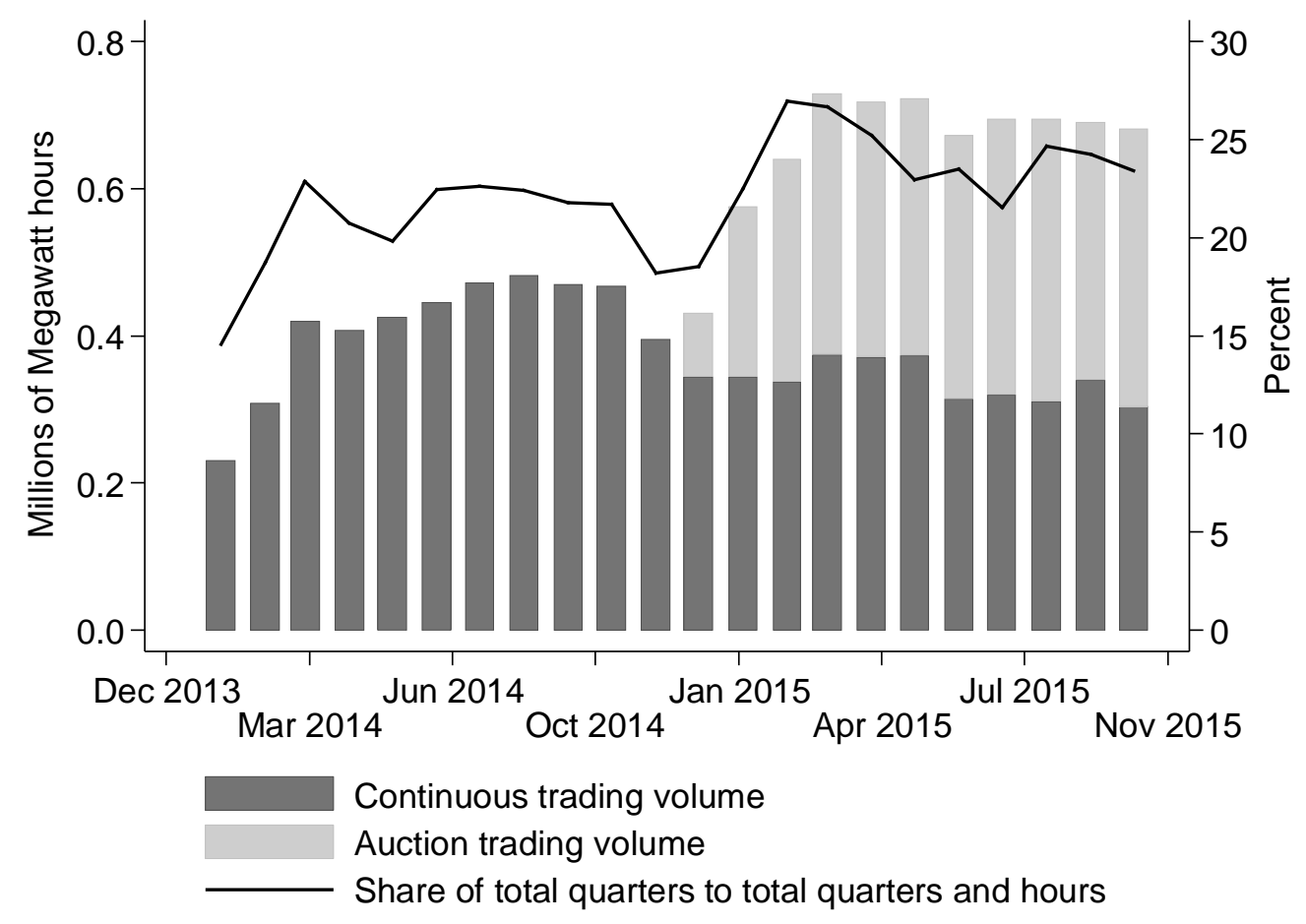

\section{Insights from introduction of intraday auction}

The implementation of the $3 \mathrm{pm}$ auction for 15 minute long slots offers the opportunity to compare outcomes of auctions with the continuous market and analyze the impact of implementing an additional auction on market depths, trading volumes as well as trading prices. To this end, we identify similar time slots before and after the implementation of the auction using matching techniques regarding the absolute levels of wind and solar electricity production, the total load as well as changes in wind, solar and total load. Similar observations before and after the implementation of the addition auction allow us to identify the impact of the additional auction at 3 pm on market depths, trading volumes and prices. Because the auction is the only systematic difference, any observed differences in outcome must be caused by this systematic difference.

In selecting comparable observations, significant problems had to be overcome. First, we accommodate for the fact that the capacity of wind and solar electricity generation capacity increases constantly, and, therefore, decided to limit our sample to observations to 90 days prior and 90 days after the implementation of the new auction. By holding the level of capacity constant, we avoid bias from omitted variables. Furthermore, as there are no equivalent holidays for Christmas and New Year in the 90 days before the implementation of the auction, we focus on the 90 days from 
Monday January 5, 2015. Thus, we also allowed for some time for traders to adjust to the new market conditions.

Of the total 17,280 15 minute time slots in the 90 days before and after the implementation of the 3 pm auction, we identified 1,288 15 minute slots with similar levels of solar, wind, total load as well their respective changes to the preceding 15 minute slot.

\section{Empirical evidence of intraday market depth}

One measure of reliability and usefulness of markets is market depth defined as the amount of electricity that is offered at certain prices at given times. The higher the market depth, the more of the available flexibility is directly offered to the market, and, therefore, the more likely it is that synergies across the system can be realized.

One interesting comparison point can be drawn from the $15 \mathrm{mn}$ auction. On the continuous market the total order book depth (for all possible prices between +3000 Euro / MWH and - 3000 Euro / $\mathrm{MWh}$ ) has been relatively limited with rarely more than $1.5 \mathrm{GW}$ offered for any one $15 \mathrm{mn}$ slot as shown in the figure 3 below.

Figure 3: Order Book depth on the 15mn Continuous Intraday market

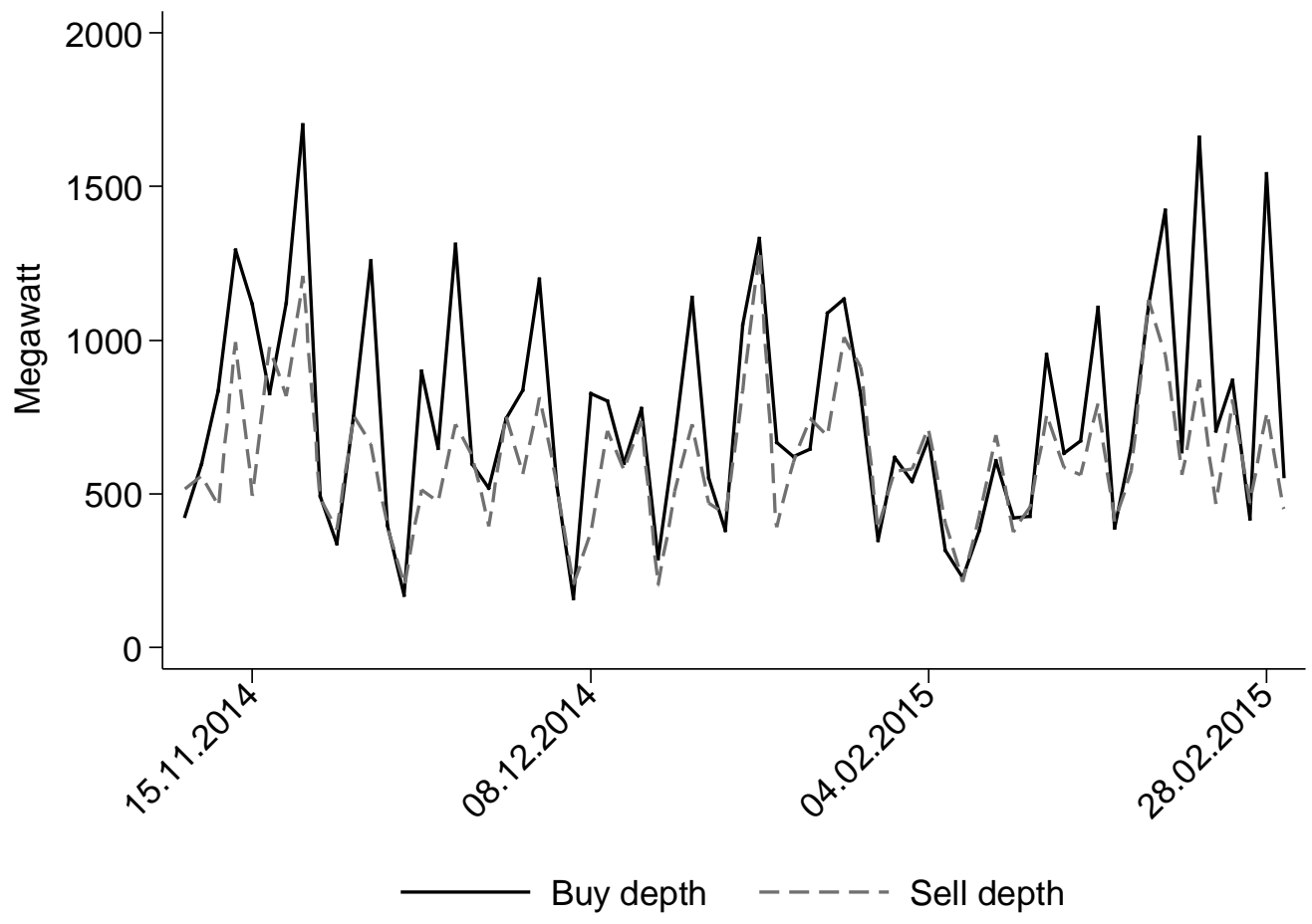

Figure 4 indicates the market depth in terms of supply and demand at respectively the highest possible and lowest possible prices at the 15 minute auction. ${ }^{6}$

\footnotetext{
${ }^{6}$ The market depth can also be calculated at prices other than +-3000 Euro. However, we deem the maximum values for the least arbitrary.
} 

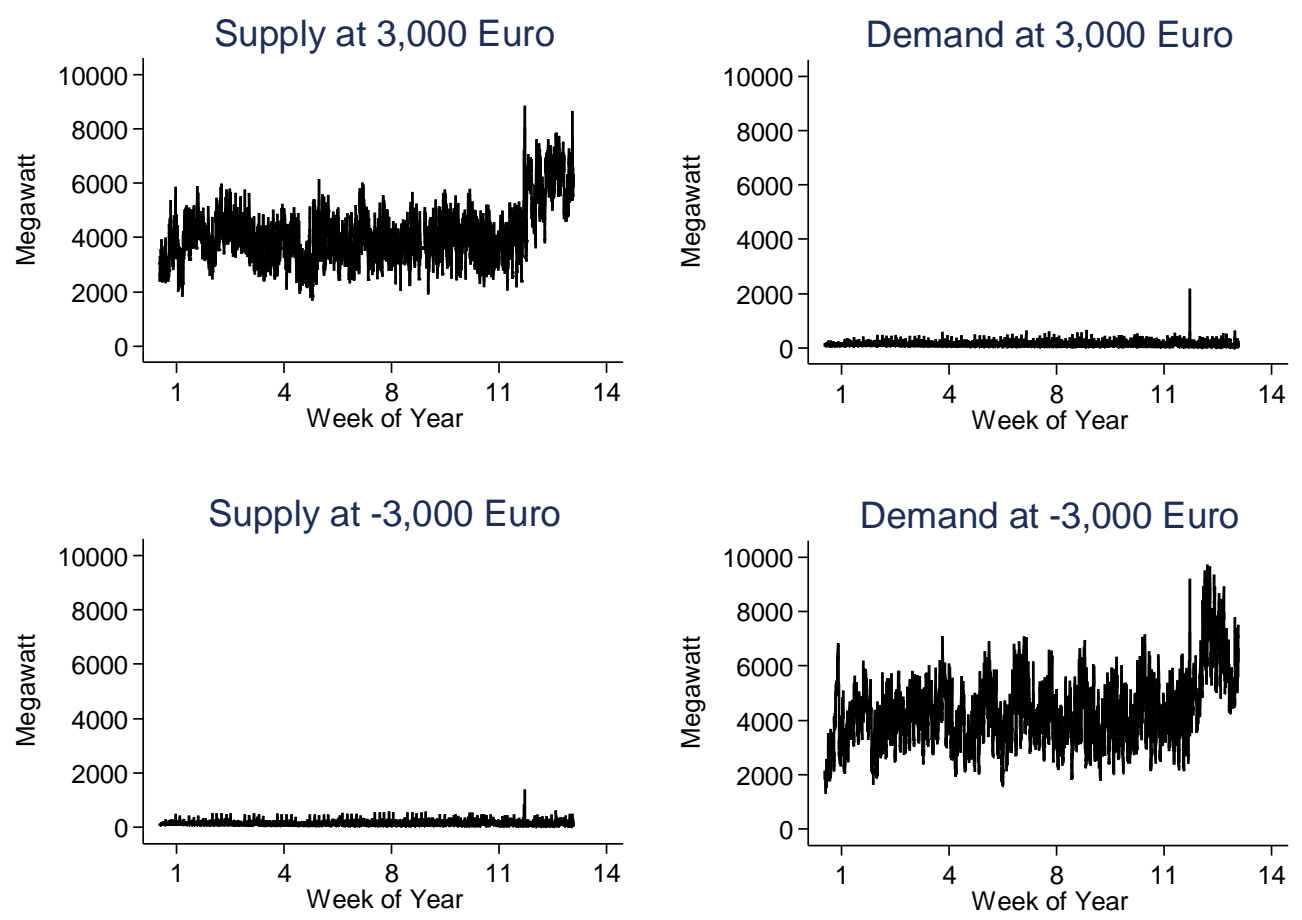

With the intraday auction much higher volumes are offered to the market ${ }^{7}$. During the auctions on average $4 \mathrm{GW}$ (per $15 \mathrm{mn}$ slot) of capacity have been offered to the market (on the sale side), with average offer volumes of about $5 \mathrm{GW}$ (per $15 \mathrm{mn}$ slot) since March 2015 and a maximum of $9 \mathrm{GW}{ }^{8}$ This is illustrated in Figure 5 at the example of bids and offers for March 15, 2015 submitted to the 15 minute auction at 3pm for the 15 minute product from 12:00 CET to 12:15 CET. As expected, most bids and offers are priced below $100 € / \mathrm{MWh}$. However, offers that are only available at prices exceeding hundreds of $€ / \mathrm{MWh}$ are also submitted. If, for example, an offer of at least $500 € / \mathrm{MWh}$ is required to clear the price, then this will set the price for all energy cleared in the auction.

\footnotetext{
${ }^{7}$ Weiyu K, and Yu-Ching L, (2011) analyze trading mechanism in the Taiwan Futures Exchange (TAIFEX) after the switch from an exclusive call market to a continuous auction market find that while the quoted spreads, effective spreads, and price volatility are all smaller in the continuous auction market, the call auction market exhibits greater market depth and smaller pricing errors. They conclude the choice between call and continuous auction trading mechanisms essentially involves trade-offs between the bid-ask spread, market depth, price volatility, information asymmetry costs, and price efficiency.

${ }^{8}$ This increase happened with the solar eclipse delivery day (20 March 2015) which was anticipated to create challenges for the system and thus likely encouraged market participants to further explore how flexibility can be provided to or obtained through the market. There was no subsequent drop - indicating that once the understanding and systems are in place they will continue to be used.
} 


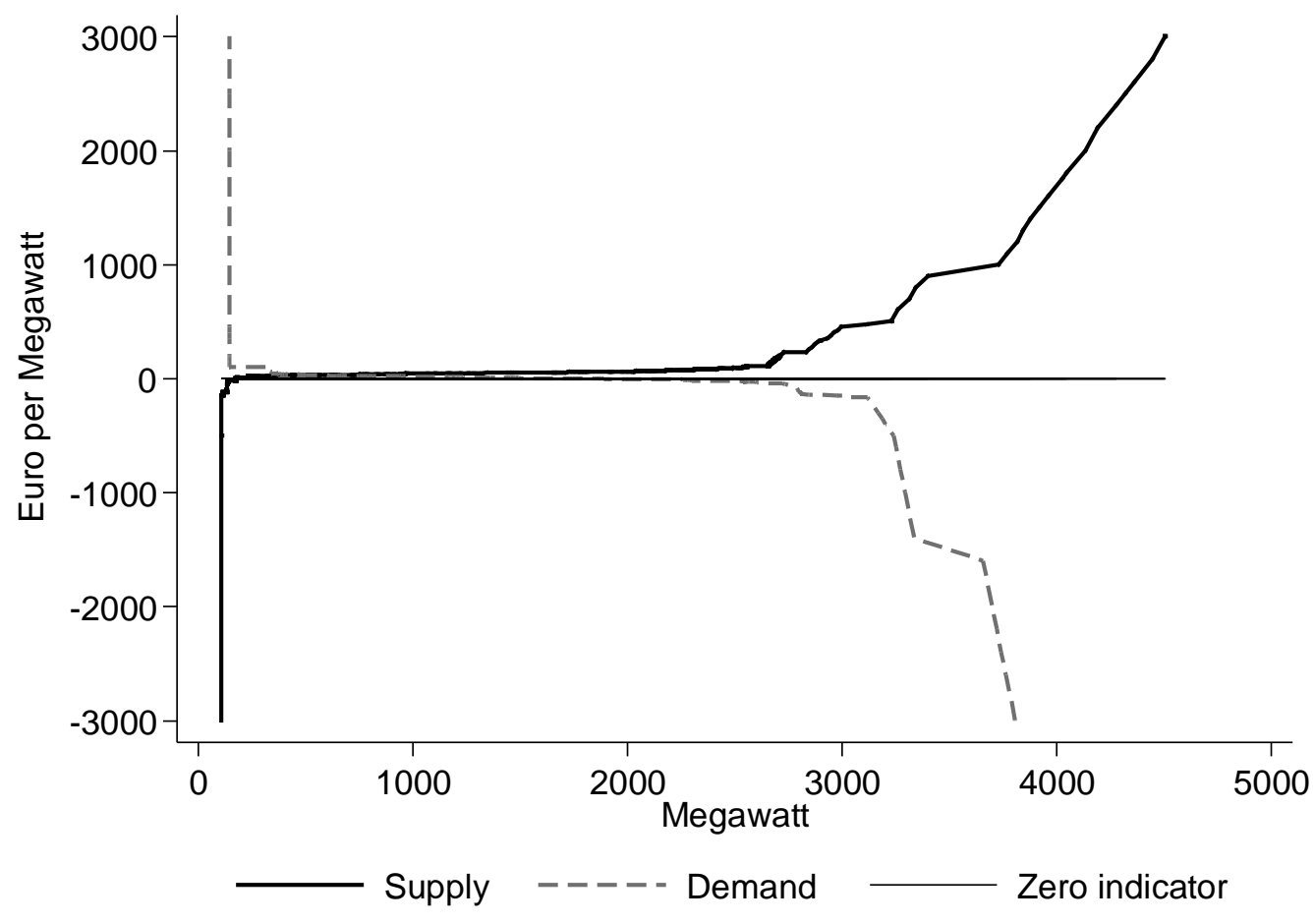

This pricing approach may explain the difference of the depth of a limited order book and the uniform price auction. In a uniform price auction, market participants can offer all available capacity at marginal costs and the uniform clearing price ensures remuneration the value the capacity required by the system. In contrast, in a continuous auction, market participants have to anticipate/negotiate the market clearing price and incorporate accordingly a mark-up in their offers in order to capture the value of generation assets to the system. However, this value to the system may change, for example if scarcity increases with the failure of a power station. Therefore, market participants only submit limited order for a fraction of their available capacity so that they can submit additional limited orders with adjust mark-ups should the supply-demand balance change.

\section{Empirical evidence regarding trading volumes}

One further measure of reliability and usefulness of markets is market liquidity, e.g. the volume of transactions pursued in the market. All else equal, the higher the market liquidity, the higher the possibility and the lower the transaction costs to find a trading partner.

A comparison of trading volumes between the similar observations before and after the implementation of the $3 \mathrm{pm}$ auction shows that total trading volume has significantly increased. The auction currently trades more at the opening compared to the total continuous market for 15 minute slots, with regular volumes above 50,000 Megawatt (MW) or 12,500 Megawatt hours (MWh) traded per day, while on the continuous market the volume rarely exceeded 6,000 MWh at the opening.

Figure 6 indicates the impact of the implementation of the $3 \mathrm{pm}$ auction for 15 minute slots. The graph indicates the bootstrapped standard errors for the average volumes in the continuous trade before and after the implementation of the $3 \mathrm{pm}$ auction for select percentiles. Non-overlapping 
confidence intervals indicate that the difference is statistically significant at the point of interest. In case of overlap, only a statistical test can inform about significance. The reader learns that the volume has doubled for 15 minute products that were previously not traded liquidly and has increased by $20-30 \%$ for other 15 minute products. This increase is only due to the additional trading volume on the auction platform that has more than compensated a small reduction of continuous trading that has predominantly occurred for those 15 minute slots for which trading was previously already high.

Figure 6: The effect of the $3 \mathrm{pm}$ auction on the continuous trade volume

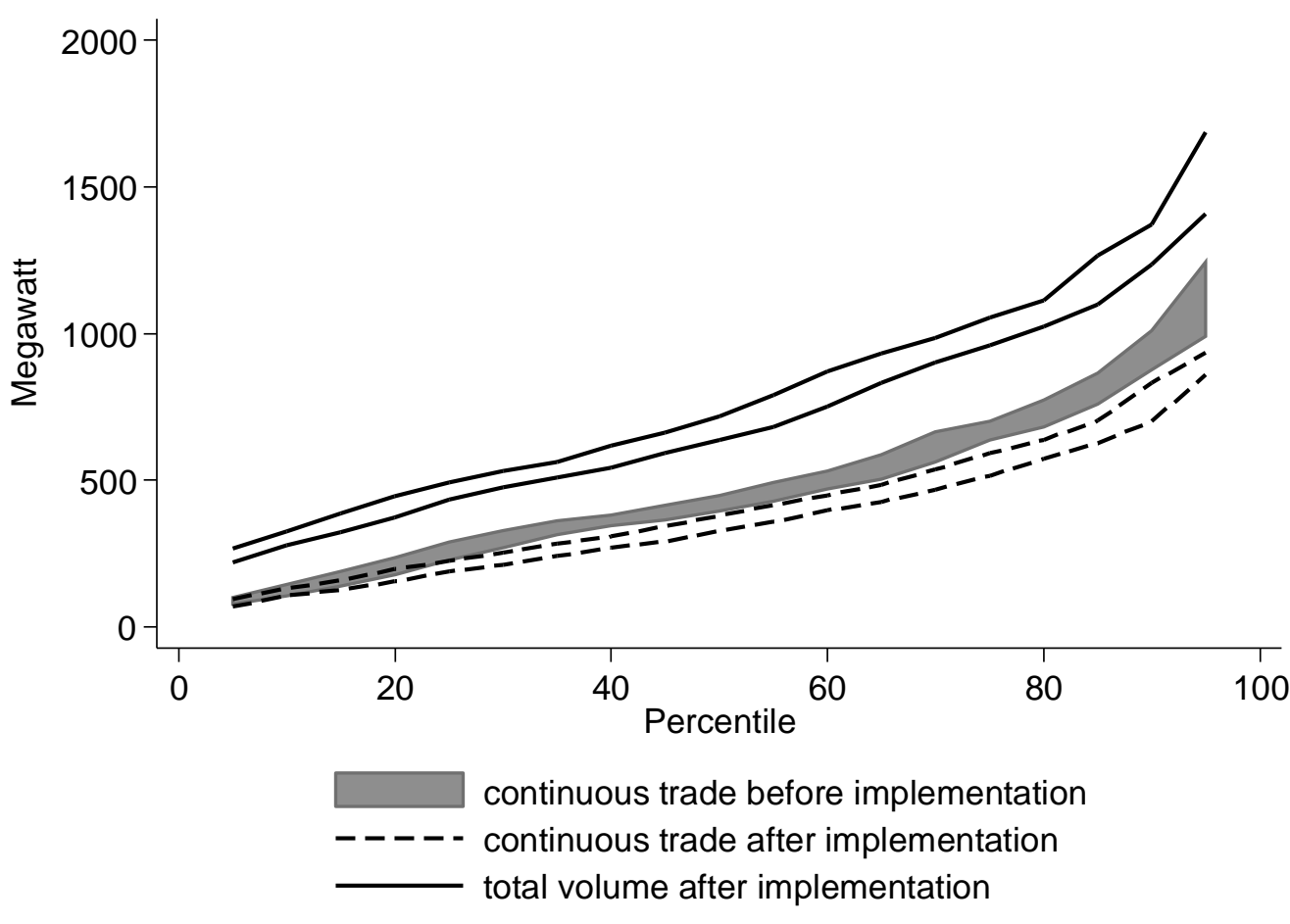

Figure 7 depicts this information for select delivery times, indicating the continuous trading volume for similar 15 minute slots before and after the implementation of the $3 \mathrm{pm}$ auction. With the exception of the auction for 6.00 am products, trading volumes appear similar before and after the implementation of the auction. As the trading volumes are volatile, the differences are statistically not significant. This is in line with the overall picture from Figure 5. 

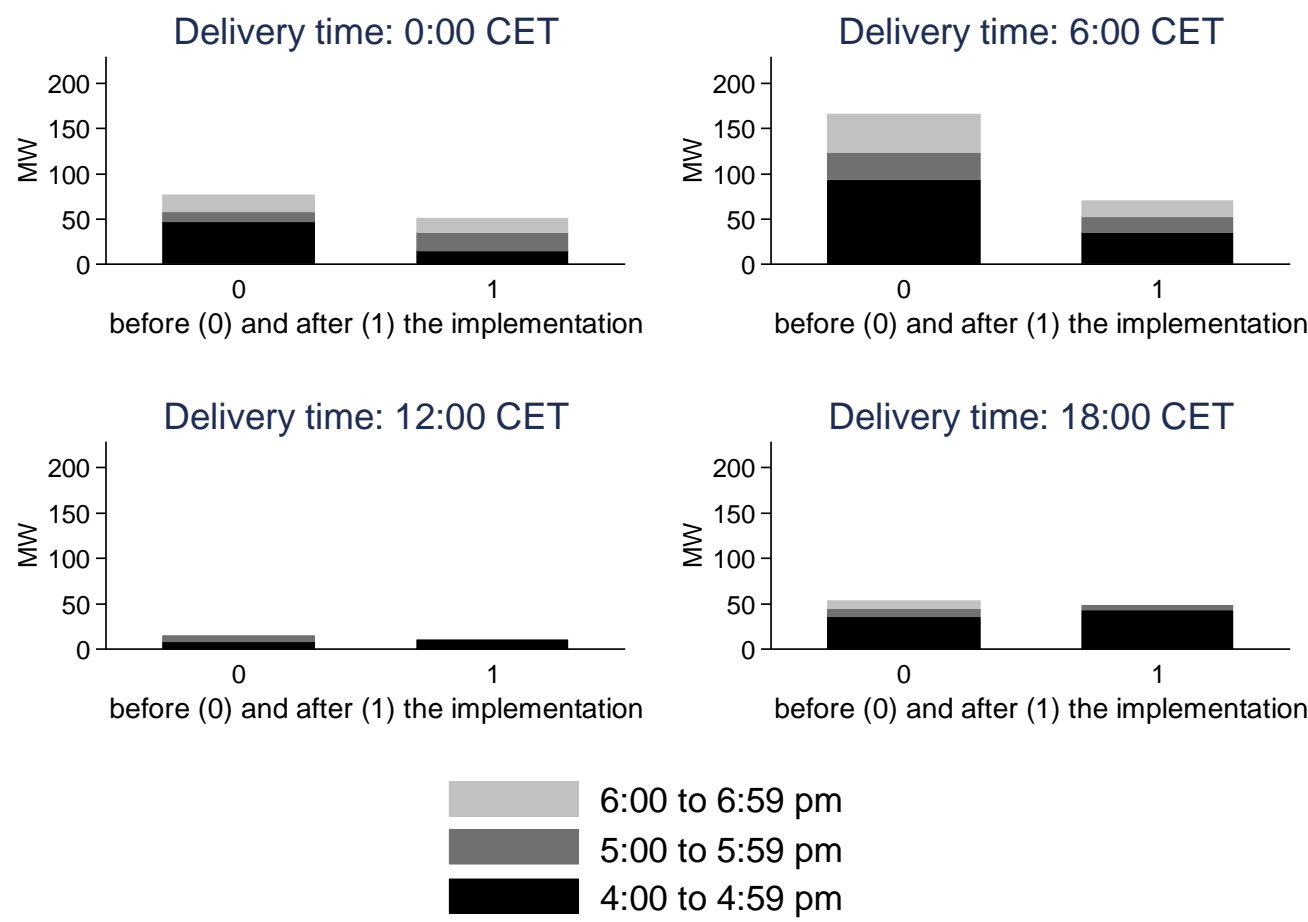

Figure 8 indicates the trading volumes in the last 3 hours before delivery for select 15 minute slots. In comparison to Figure 6, the trading volumes in the last hours are significantly higher. However, there is no statistical evidence that would suggest that the implementation of the $3 \mathrm{pm}$ auction at the beginning of the trading day has had any impact on trading volumes at the end of the intraday period. In fact, this would be counter intuitive because the trading in the last hours before delivery accommodates for unexpected events in supply or demand, such as deviations from expected renewable electricity production or unscheduled maintenance requirements and equipment failures (forced outages).

Altogether, the comparison of similar quarters before and after the implementation of the $3 \mathrm{pm}$ auction indicates that auctions increase the total amount of trade, while the impact on the level of the continuous trade is limited. One possible explanation for the observed pattern is that electricity producers align electricity production profiles with the delivery profiles contracted using the new 3 pm auction. In this case, continuous trading was used to align profiles and accommodate new information before the implementation of the $3 \mathrm{pm}$ auction, while continuous trading after the implementation is largely used to accommodating for new information. 

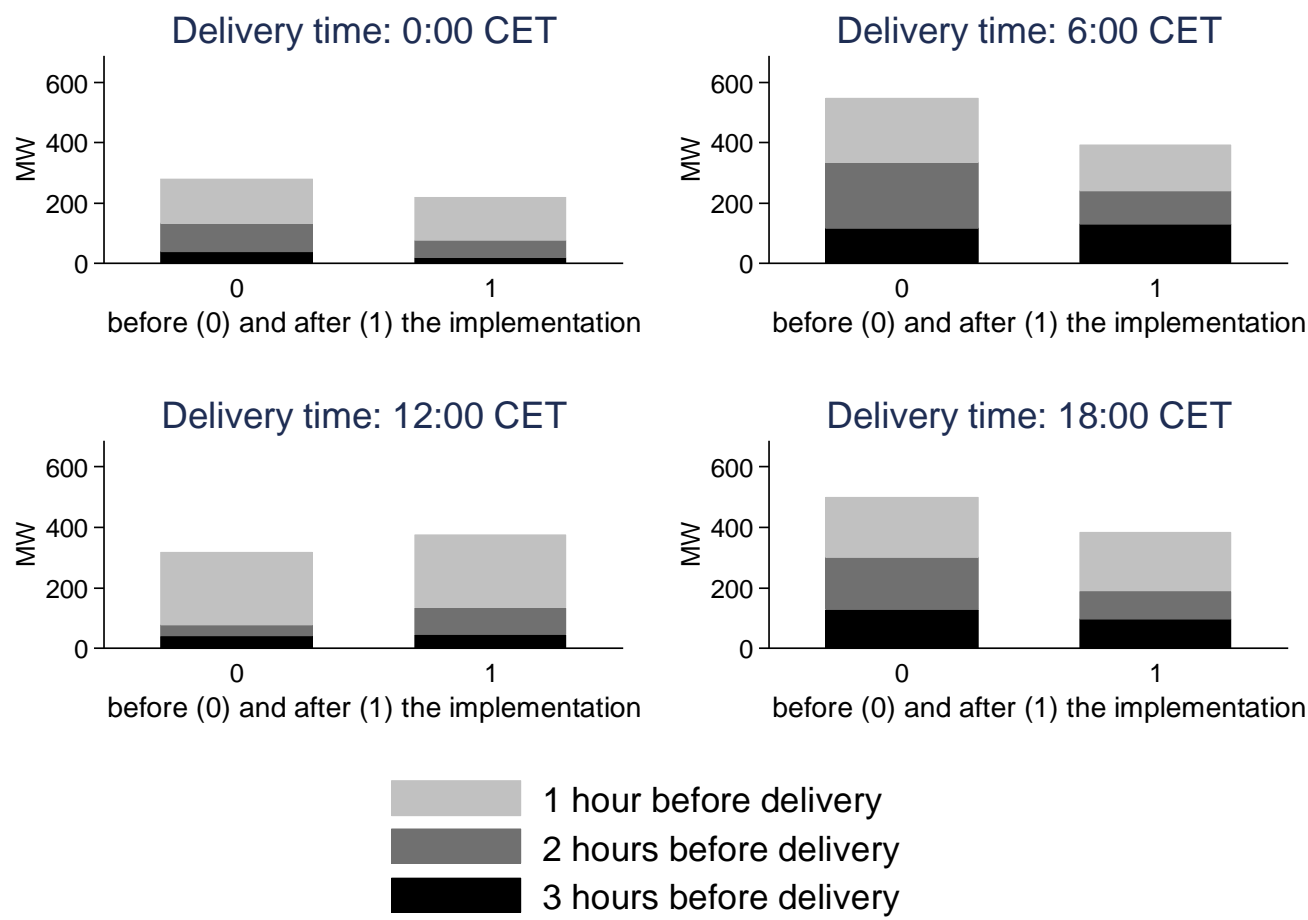

\section{Empirical evidence regarding the impact on prices}

In addition to the impact on trading volumes, we were interested to find out whether the implementation of the auction at $3 \mathrm{pm}$ had an impact on the variance of the price in the first 3 trading hours. We believe that the auction sets a strong price signal and reduces said variance. Therefore, we test the hypothesis that the auction has led to a reduced price variance. The rational is that in case no new information arises, the continuous trade in the first few hours after the auction should be informed by the auction price.

The test results in Table 1 are indicated in the form of $p$-values. The null hypothesis is that the variance of the price before is higher compared to the variance after the implementation of the $3 \mathrm{pm}$ auction. In case that the p-value for such a test is equal to or below 0.05 , the null hypothesis is rejected. In case of rejection, the variance before is significantly higher compared to the variance after the implementation. The number of observations on which the tests are conducted is indicated in parentheses below the p-value.

Table 1 indicates that for all but 2 combinations of trade and delivery time, the variance of the price was lower for observations after the implementation of the auction compared to similar observations before the implementation. This leads us to conclude that the new auction at $3 \mathrm{pm}$ sets a strong price signal and reduces the variance of the price. 
Table 1: Test results indicating influence of auction on price variance

\begin{tabular}{|l|l|l|l|l|}
\hline Time of Trade & \multicolumn{4}{|l|}{ Delivery Time } \\
\hline & $0: 00$ CET & $6: 00$ CET & $12: 00$ CET & $18: 00$ CET \\
\hline $16: 00-16: 59$ CET & 0.000 & 0.000 & 0.000 & 1.000 \\
\hline & $(496)$ & $(452)$ & $(38)$ & $(158)$ \\
\hline $17: 00-17: 59$ CET & 0.000 & 0.003 & & 0.247 \\
\hline & $(163)$ & $(95)$ & & $(25)$ \\
\hline $18: 00-18: 59$ CET & 0.000 & 0.000 & & \\
\hline & $(169)$ & $(113)$ & & \\
\hline
\end{tabular}

\section{Considerations for introduction of intraday auction}

\section{Reference price for derivative products}

In Europe, longer-term financial products are referenced to the price at the day-ahead auction. However, at the day-ahead stage, the final production remains uncertain, especially that of wind and solar production. Therefore, the day-ahead price only reflects an average of potential outcomes and more volatility prices closer to real time. To reflect the full value of peaking capacity and flexibility products in longer-term products, a reference price in real time or close to real time is therefore desirable.

To achieve this objective in continuous trading arrangements, EPEX calculates the volume weighted average price of all trades during the last three hours before gate closure. This average price is used as a reference for Cap-Futures introduced in September 2015 (EPEX 2015b). In case this volume weighted price index exceed $60 €$, the holder of the cap future receives a payment on the order of the difference between the volume weighted price and the $60 €$ of the cap.

However, in a continuous trading arrangement, an asset offering or requiring flexibility in the shortterm cannot sell this power at the average index price but only in a discrete transaction. If the price obtained in the discrete transaction deviates from the index price, then products like the Cap-Future do not provide a complete hedge so that some basis risk remains.

To assess the scale of this basis risk, we calculated the volume weighted price index for the cap futures for the time from January 1, 2014 through April 30, 2015 based on 2,552,831 trades in the continuous market. In 163,330 cases, the contracted price was above 60 Euro per Megawatt hour. However, only in 70,860 cases $(43.4 \%)$ did the volume weighted price exceed 60 Euro, so that the holder of the cap future received a payment. 


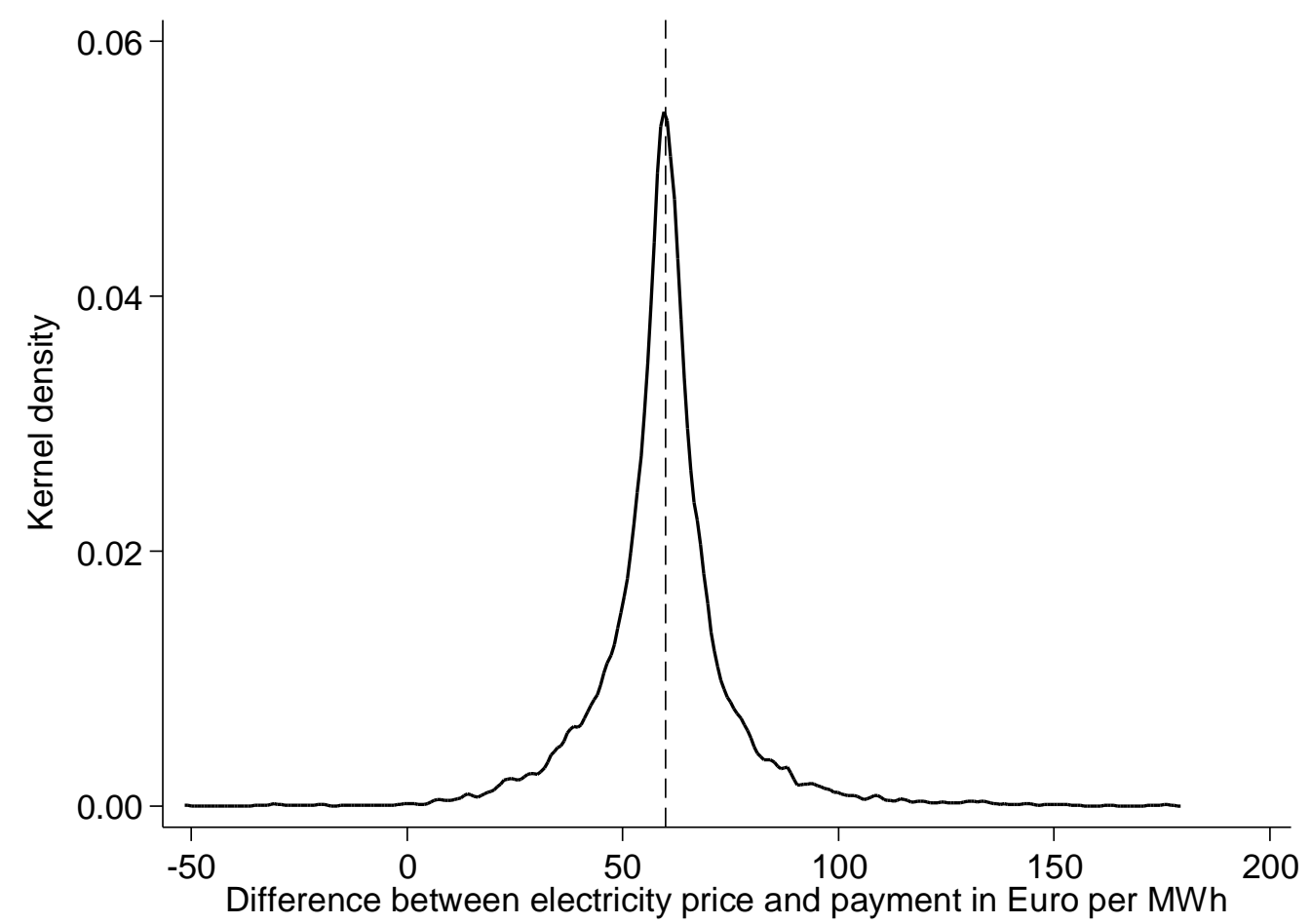

Figure 9 indicates the difference between electricity prices in individual intraday transactions and payments from the cap-future for the relevant period. Without basis risk, the difference should in all instances be $60 € / \mathrm{MWh}$, as the option contract pays out the difference to the strike price. However, as can be seen the basis risk is significant. In $5 \%$ of the transactions the basis risk is more than 86 $€ / M W h$. Altogether, this indicates that the cap futures referenced to an index based on continuous trading only offers limited capacity to hedge against price risks. In contrast, if a similar option contract would have been referenced to a uniform price auction, then it hedges market participants trading in this auction without basis risk.

\section{Bringing the full flexibility to the market}

Continuous exchange based intraday trading is primarily used for the implementation of small adjustments to production and consumption. It is being reported that in response to large adjustment needs, for example from the failure of a power station, market participants are more inclined to negotiate bilaterally. This allows the buyer to characterize the needs across consecutive hours and the provider of short-term response to make more comprehensive adjustments of operational schedules, including the start-up of plants.

In principle, market participants can express their flexibility offers or requirements using block bids. For example, for conventional power generators the production in consecutive hours is not fully independent. They face start-up and shutdown costs, minimum run requirements, and can only gradually adjust their production (ramp rates). A classical block order has an all-or-none constraint and only clears if all energy offered (or requested) for the specified hours is accepted.

On the continuous market, the number of matched block bids is significantly lower than the number of matched blocks in the auction. The reason is that on the continuous market each block on the sell side needs to be matched with a block on the buy side, unless a cross-matching algorithm is 
implemented. However, the permutation problem that this cross-matching engine needs to address when taking into account several borders (network topology) and products (15/30/60 mn) becomes quickly intractable for an instantaneous/immediate execution.

In the case of an auction, it is the algorithm that executes the block using a discrete block of time and a number of different products. Figure 10 shows the combinations for a simple $3 \mathrm{MW}$ hourly product that can be filled by $15 / 30 / 60 \mathrm{mn}$ contracts and matching a block with any type of orders. There is a non-linear increase in the number of combinations to create blocks when there are different borders involved and different available products. The complexity of the problem increases exponentially with the number of borders, the number of products, and the size of the blocks.

Figure 10: Matching a simple 3MW hourly order with hourly, half-hourly or quarterly order combinations

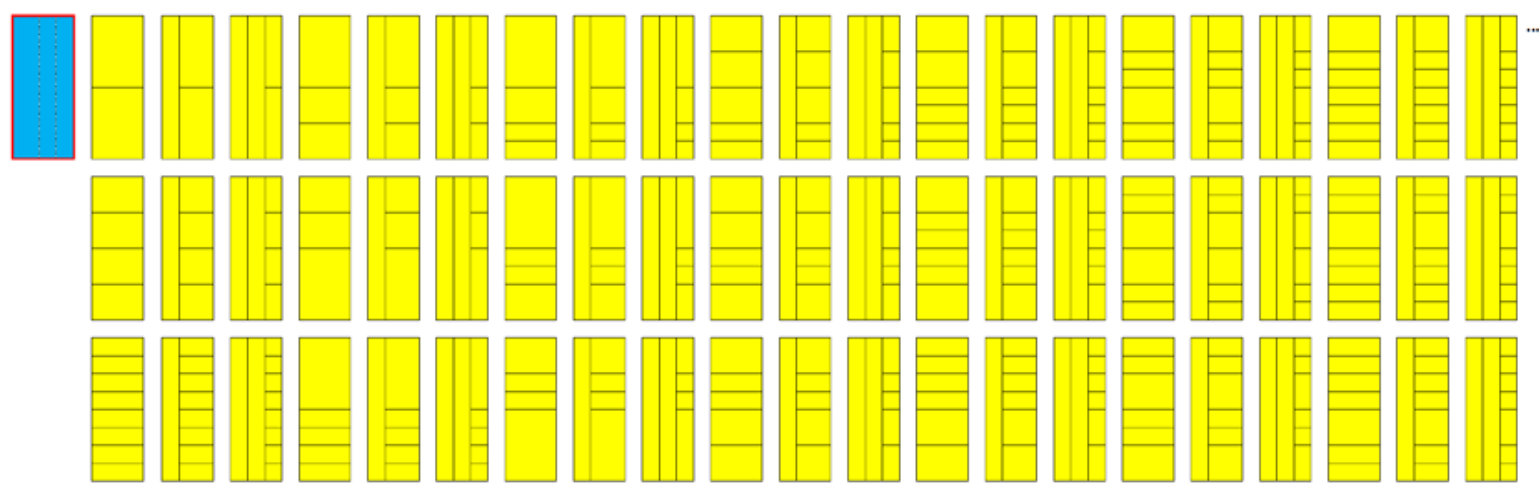

Because auctions typically allow for a longer calculation time, auctions ensure a better execution/matching of blocks that allow generators to offer energy in consecutive hours taking into account technical and economic requirements. This turns the day-ahead auction into a type of combinatorial double sided uniform price auction ${ }^{9}$. The structure how block orders can be formulated differs in EU member states and has not been fully harmonized. In most North-western European countries where power exchanges are voluntary and compete with OTC, similar standard and smart blocks ${ }^{10}$ are offered on the auction. In Spain and Italy which are mandatory pools complex orders such as MIC (Minimum Income Orders) and Load gradient orders, merit orders and PUN orders (Prezzio Unico Nazionale) are also available.

Therefore it needs to be considered whether the bidding format is harmonized to improve efficiency of the market result. Furthermore, in order to realize the full flexibility of all generation assets, the format of multi-part bids may offer an attractive perspective (Neuhoff et al. 2015 b): The bids are based on variable costs but can also comprise elements like ramping constraints and start-up costs. Thus market participants can offer all their flexibility, while the combinatorial complexity linked to block bids could be tackled through longer computation time.

\footnotetext{
${ }^{9}$ Combinatorial auctions are described in Cramton P., Y. Shoham and R. Steinberg (2006

${ }^{10}$ A more detailed description of smart block types (Linked blocks, exclusive groups and flexible bocks) can be found in the PCR (2014) algorithm description and functioning.
} 


\section{Ensuring secure operation of the market}

As in all commodity/financial markets, traders in the continuous intraday power market have been developing and connecting automated trading tools (through the open Automated Programming Interface or API) of the power exchange that allows connecting software applications that can directly read/write in the order book). This allows them to define automated trading strategies and thus benefit from arbitrage opportunities that arise in the continuous order book.

This penetration of algorithmic trading means higher trading speeds, higher turnover rates, but most importantly higher order-to-trade ratios (number of order submissions/modifications to make one transaction). Although trading in power markets cannot yet be characterized as high frequency trading (i.e. nanoseconds), the order submissions have increased dramatically over the last two years. It is not rare that the number of orders on the German power market over a given trading day exceeds 100,000 orders.

While processing any single order is computationally trivial, even a trivial operation takes nonzero computational time, which implies that during surges of activity there will be backlog and processing delay. This backlog can lead to confusion for trading algorithms, which are temporarily left uncertain about the state of their own orders and the state of the limit order book. Backlog is most severe at times of especially high market activity (Budish et al. 2014).

This trend towards automation has accelerated significantly over the past two years as more trading houses plug automated trading tools on the API. This raises a question for the need for speed and the benefit that this brings to the wider market. But it also raises the issue of the reliability of the intraday market which is challenged by increased load (massive order submissions). The escalating volume of bids and offers is challenging for a secure operation of the market as it coincides with increasing numbers of interruptions to the operation of the continuous intraday trading platform. Thus, it ultimately may pose a risk for the reliability of the power system operation that increasingly depends on well-functioning intraday markets.

There should be no discussion on the automation need in the power market. However, the benefit of a race for speed is debatable. Although this question is complex, some elements can be found when comparing the power market with financial markets. Are automated traders making the market more liquid (improving the bid/ask spread)? Figure 11 below shows the distribution of the bid-ask spreads for the observed period. In the observed period the bid/ask spread has not decreased, although the number of automated trading applications connected has almost doubled.

Therefore, one advantage of auctions is that by "discretizing" the trading sessions they remove the speed advantage. This is well documented in Budish et al. (2014) who advocate for the replacement of continuous trading by frequent batch auctions ${ }^{11}$.

This is not to argue, that opportunities for intraday adjustments should be eliminated. Henriot (2014) and Garnier and Madlener (2014) show that with remaining uncertainty about wind output, wind generators will not adjust their position according to updated best estimate of wind forecast but might (i) delay adjustments until forecasts are more precise and (ii) only adjust to some of the changes in forecast to limit cost. Too infrequent intraday auctions could thus result in delayed adjustments during intraday time-frames.

\footnotetext{
${ }^{11}$ This was already suggested by Willems, B., (2011) for the intraday power market.
} 
This shows that the appropriate frequency of intraday auctions remains an important design question. Bid formats that allow for standing orders to remain valid for consecutive intraday auctions can allow for higher frequency without additional transaction costs. It may also be considered whether additional auctions are implemented closer to real time to increase the frequency.

Figure 11: Moving average of Bid/Ask-Spreads using 15 observations

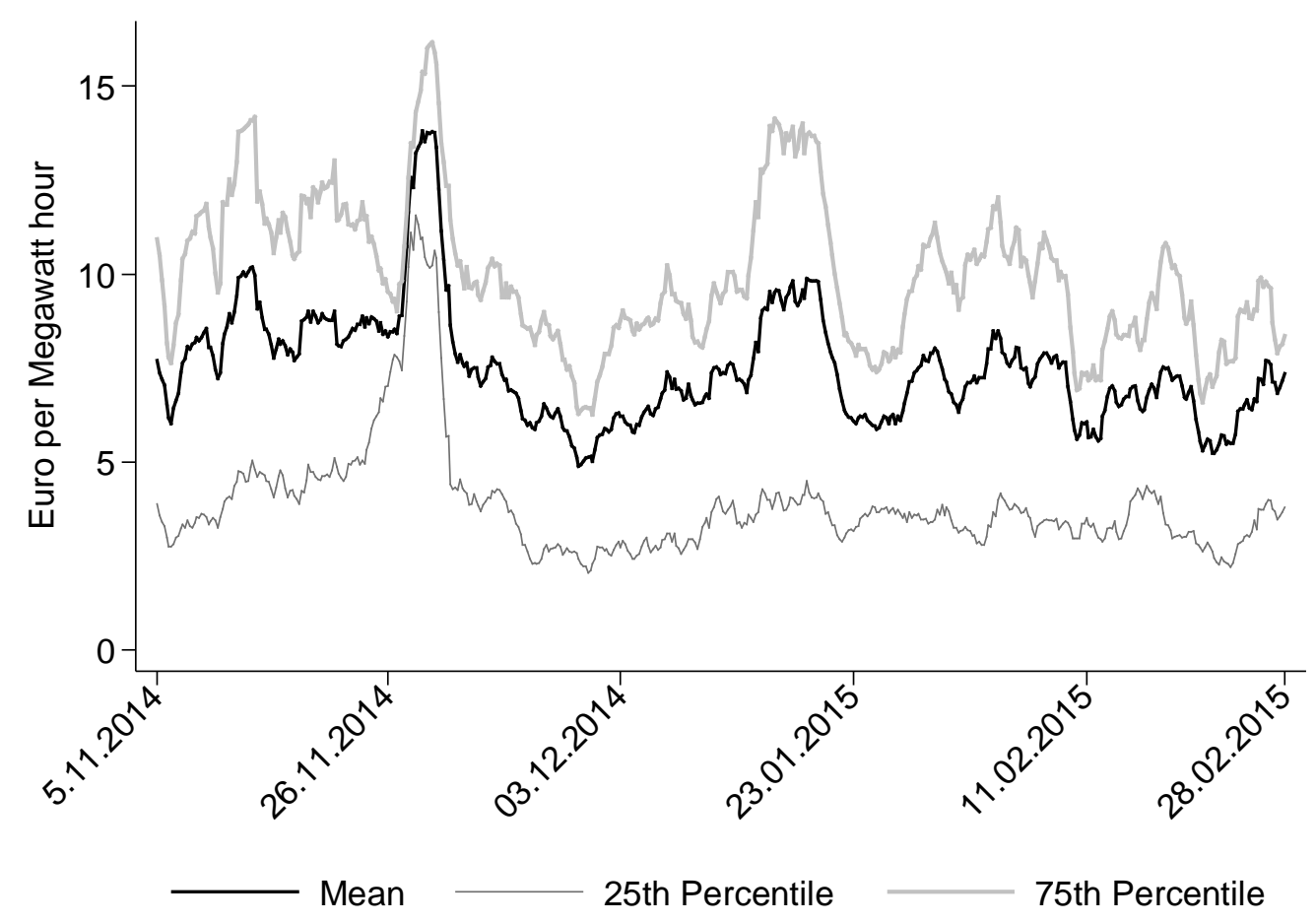

Auctions are operationally simpler for the exchange. Uniform-price auctions are easier to compute, and exchange computers can be allocated a discrete block of time during which to perform this computation. By contrast, in the continuous limit order book market design, exchange computers are not allocated a block of time during which to perform order processing, but instead process orders and other messages in serial order of their arrival ${ }^{12}$. A wider use of intraday auctions could reduce the opportunities and volume of automated trading and thus reduce the number of technical malfunctions in the market.

\section{Allocation and pricing of cross-zonal transmission capacity}

In continuous trading, it is not trivial to price transmission capacity. If the transmission price is set exante, it will, first, inhibit efficient trades if it is set too high, and, second, transfer rents to traders if it is set too low. Moreover, traders risk losses on transactions, if the price is set ex-post and the charge for transmission exceeds the trading margin. Overall, allocation of cross-zonal capacity is more evident with auctions.

\footnotetext{
${ }^{12}$ Farmer, J,D, Skouras S (2012) and Budish et al. (2014) raise this issue of system reliability on continuous markets.
} 
Therefore, transmission capacity in intraday is allocated for free on a first come first serve basis in the present Over The Counter (OTC) and exchange based continuous trading ${ }^{13}$. Thus, the potential scarcity value of transmission capacity is captured by the first mover reserving the capacity explicitly or by the best offer on the exchange screen. The first come first serve rule on the explicit allocation is favoring rapid traders instead of efficient ones. Auctions with market coupling at the day-ahead stage have demonstrated, that the benefit of coordinated auctions, as transmission capacity is implicitly auctioned, so that the scarcity value can be captured and used, either to reduce transmission tariffs or fund new transmission investment.

Furthermore, if transmission capacity is priced in the intraday market via auctions, then this can allow for a flow-based allocation of transmission capacity. This allows for the reconfiguration of flows, for example to free up transmission capacity that is used to arbitrage small price differences between two zones towards providing additional import capacity into a country with high scarcity prices.

\section{Conclusion}

For the market design of the European power markets, the $15 \mathrm{mn}$ intraday auction introduced in Germany in December 2014 gives an interesting comparison point between auctions and continuous trading. The most obvious benefits are for small market players not equipped for continuous $24 / 7$ trading and in terms of price revelation (from the start of the intraday market). We have investigated the behavior of the $15 \mathrm{mn}$ intraday market through some key indicators of market efficiency such as liquidity/market depth and price volatility. We observe that the additional auction increases liquidity, leads to a higher market depth (the revelation of market participant's capacity/flexibility) and to a reduced price volatility.

This paper highlights in a more qualitative way some additional features associated with auctions, such as their contribution to security of operation through a higher operational reliability, the deterrence of the high frequency continuous arms race, the setup of a reference point in terms of liquidity for the settlement of hedging products (that will be pivotal in a market with a very large share of renewables where volatility as hedging needs are expected to increase), the facilitation of a more efficient allocation of transmission capacity intraday (notably by enabling flow-based allocation), and guarantee that scarcity value of transmission capacity is signaled and can contribute to reduced transmission costs for consumers.

Future research should focus on the design features of such auctions. In particular it will be important to evaluate bid formats that allow market participants to provide full flexibility to the market, while facilitating rapid market clearing. Promising options such as multi-part bids can accommodate different physical/technical needs. Also the frequency at which intraday auctions are executed warrants further analysis of potential trade-offs between market/position re-balancing opportunities and liquidity - as well as opportunities of bid formats that are compatible with standing orders and can thus combine market depth with higher frequency auctions. Finally, the use of the available cross-zonal capacity by the auction should be assessed. This important question is linked to the accuracy of information provided to the TSO and the way the TSOs will re-calculate the

\footnotetext{
${ }^{13}$ This is also the principle envisaged for the shared order book to be implemented in XBID by 2017.
} 
available intraday cross-zonal capacity, the frequency of the intraday auctions, and how the access to the cross-zonal capacity is shared with continuous markets. 


\section{References}

BNetzA (2014), Monitoring report 2014

Budish, Eric, Peter Cramton, and John Shim. (2014) "Implementation details for frequent batch auctions: Slowing down markets to the blink of an eye." The American Economic Review 104.5: 418424.

Chaves Avila J.P. (2014) European Short-term Electricity Market Designs under High Penetration of Wind Power, PhD Dissertation TU Delft.

Cramton P., Y. Shoham and R. Steinberg (eds.) (2006), Combinatorial Auctions, MIT Press, ISBN 0262033429.

EPEX (2015) EPEX SPOT and ECC successfully reduce lead time on all intraday markets, European Power Exchange, Paris, https://www.epexspot.com/en/pressmedia/press/details/press/EPEX_SPOT_and_ECC_successfully_re duce lead time on all intraday markets.

EPEX (2015b) EEX European Power Futures and Introduction of Cap Futures, European Power Exchange, Paris, https://www.google.de/url?sa=t\&rct=j\&q=\&esrc=s\&source=web\&cd=2\&cad=rja\&uact $=8 \& v e d=0 C C$ MQFjABahUKEwjWrOHvkoHJAhXDEiwKHZnuCKk\&url=https\%3A\%2F\%2Fwww.eex.com\%2Fd ownload\%2Fen\%2F84618\&usg=AFQjCNHaIRiL1puYejlqcJUO8XThs0bwMA\&bvm=bv.106923889 d.bGg.

Farmer, J,D, Skouras S (2012), Review of the benefits of a continuous market vs. randomized stop auctions and of alternative Priority Rules (policy options 71 and 12), European Commission Public Consultation, Review of the Markets in Financial Instruments Directive

Garnier E, R. Madlener (2015) Balancing forecast errors in continuous-trade intraday markets, Energy Syst 6:361-388.

Hagemann S. and C. Weber (2015) Trading volumes in intraday markets - theoretical reference model and empirical observation in selected European markets, EWL Working Paper No. 03/15

Henriot A. (2014) Market Design with Centralized Wind Power Management: Handling Lowpredictability in Intraday Markets, The Energy Journal, Vol. 35, No. 1.

Neuhoff K, Carlos Batlle, G. Brunekreeft, C V. Konstantinidis, C. Nabe, G. Oggioni, P. Rodilla, S. Schwenen, T. Siewierski, G. Strbac (2015a) Flexible Short-Term Power Trading: Gathering Experience in EU Countries, Discussion Papers of DIW Berlin 1494.

Neuhoff, K, N. Ritter, S. Schwenen (2015b) Bidding Structures and Trading Arrangements for Flexibility across EU Power Markets, Report from the Future Power Market Workshop 2015, held at Ofgem, London, June 26 
Price Coupling of Regions (2014) EUPHEMIA Algorithm description and functioning. https://www.epexspot.com/document/33195/Euphemia\%3A\%20Public\%20documentation\%20$\underline{\% 20 S e p \% 202015}$

Ramteen Sioshansi, Shmuel Oren b,*, Richard O’Neill c, “Three-part auctions versus selfcommitment in day-ahead electricity markets”

Smeers, Y., 2008. Study on the General Design of Electricity Market Mechanisms close to Real Time. Université Catholique de Louvain, School of Engineering [INMA] and Core.

Vassilopoulos, P, Salah, A (2013), “The Intraday Paradigm: An Agile Market to Remunerate Flexibility and Integrate Intermittency”, Cambridge Energy Research Associates.

Weber, C., 2010. Adequate Intraday Market Design to Enable the Integration of Wind Energy into the European Power Systems. Energy Policy, 38(7): 3155-3163.

Weiyu K, and Yu-Ching L, (2011), Trading Mechanisms and Market Quality: Call Markets versus Continuous Auction Markets, International review of Finance

Willems, B., 2011. Intraday-trade: Economics refresher (Presentation). Tilburg University, Tilec Tilburg Law and Economics Center. 